\title{
Eletrodeposição de ligas Mn-Co em aço inoxidável ferrítico AISI 430 a partir da reciclagem de baterias íon-Li: aplicação em interconectores das PaCOS
}

\author{
"Electrodeposition of Mn-Co alloys on steel \\ AISI 430 ferritic stainless steel from Li-ion \\ battery recycling: application in PACOS interconnectors"
}

\author{
Sicele Luciana Abreu Gonçalves ${ }^{1}$, Eric Marsalha Garcia ${ }^{2}$, \\ Hosane Aparecida Taroco ${ }^{2}$, Tulio Matencio ${ }^{1}$
}

\footnotetext{
${ }^{1}$ Laboratório de Materiais e Pilha à Combustível (LaMPaC), Departamento de Engenharia Química (UFMG), AV. Antônio Carlos, Pampulha,6627, CEP: 31270-901, Minas Gerais, Belo Horizonte, Brasil

${ }^{2}$ Laboratório de Físico Química, Departamento de Ciências Exatas e Biológicas (DECEB/UFSJ/CSL), Rua Sétimo Moreira Martins, Itapuã II, 188, CEP: 35701-970, Minas Gerais, sete Lagoas, Brasil.

e-mail: siceleabreu@hotmail.com, ericmgmg@hotmail.com, hataroco@ufsj.edu.br, tmatencio@ufmg.br
}

\section{RESUMO}

Um dos desafios atuais é a busca de materiais eficientes e de baixo custo para os componentes das Pilhas a Combustível de Óxido Sólido (PaCOS), já que estes dispositivos se destacam pela geração limpa de energia elétrica e alta eficiência. Dentre estes componentes está o interconector, nos quais o aço inoxidável ferrítico poderia ser utilizado na sua fabricação. No entanto revestimentos protetores são necessários para bloquear a volatilidade do cromo da superfície metálica do interconector nas condições de operação das PaCOS. Neste

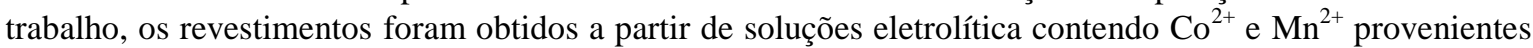
de catodos de baterias de íon lítio (BIL's) exauridas. Foram feitas eletrodeposições potenciostáticas com o objetivo de se obter ligas de cobalto e manganês sobre a superfície de amostras do aço AISI 430. Dados de eficiência de carga do processo foram calculados para otimização das amostras, e a condição de $\mathrm{pH}$ mais ácido $(\mathrm{pH}=3)$ mostrou-se menos eficiente. Contudo, o filme apresentou microestrutura homogênea, menos porosa e constituída por uma camada interna de $(\mathrm{Mn}, \mathrm{Cr})_{2} \mathrm{O}_{3}$ e externa de $\mathrm{MnCo}_{2} \mathrm{O}_{4}$, capaz de bloquear a perda do $\mathrm{Cr}$, conforme mostraram as análises de DRX, MEV e EED. Já para o pH menos ácido ( $\mathrm{pH}=3,5)$, não foi identificada a presença do $\mathrm{Mn}$ na composição do depósito, e o revestimento formado de $\mathrm{Co}_{3} \mathrm{O}_{4}$ não se mostrou capaz de bloquear a perda de cromo por volatilidade.

Palavras-chave: Interconectores, PaCOS, eletrodeposição, reciclagem, baterias de íons de lítio.

\section{ABSTRACT}

One of the current challenges is the search for efficient and low-cost materials for the components of Solid Oxide Fuel Cells (SOFCS), since these devices stand out for the clean generation of electric energy and high efficiency. Among these components is the interconnector, ferritic stainless steel can be used in its manufacture. However, protective coatings are necessary to block the volatility of the chrome of the metallic surface of the interconnector under the operating conditions of the PaCOS. In this work, the coatings will be obtained from electrolytic solutions containing $\mathrm{Co}^{2+}$ and $\mathrm{Mn}^{2+}$ from cathodes of exhausted lithium-ion batteries (LIB's). Potentiostatic electrodepositions will be performed to obtain cobalt and manganese alloys on the AISI 430 steel samples surface. The charge efficiency data were calculated to optimize the samples, and the more acidic $\mathrm{pH}$ condition was shown to be less efficient. However, the film showed a homogeneous microstructure, less porous and composed of an internal $(\mathrm{Mn}, \mathrm{Cr})_{2} \mathrm{O}_{3}$ layer and an external $\mathrm{MnCo}_{2} \mathrm{O}_{4}$ layer, capable of blocking the loss of $\mathrm{Cr}$, as demonstrated by the analyzes of XRD, SEM and EDS. For the less acidic pH, 
the presence of $\mathrm{Mn}$ in the deposit composition was not identified, and the coating formed by $\mathrm{Co}_{3} \mathrm{O}_{4}$ was not able to block the loss of chromium by volatility.

Keywords: Interconnectors, SOFC, electrodeposition. recycling, lithium-ion batteries.

\section{INTRODUÇÃO}

As Pilhas a Combustível ( $\mathrm{PaC}$ 's) são dispositivos eficientes de conversão de energia química em energia elétrica de forma limpa e renovável, além de operar com alta eficiência e potência estável. Esse fato deve-se ao tipo de combustível utilizado no processo, em que, tipicamente, o hidrogênio é o gás mais empregado. O gás oxidante é o oxigênio. Nesse caso, os produtos gerados na reação final são água e calor, o que torna as PaC's fontes verdes de produção de energia $[1,2]$.

Dentre os tipos de PaC's, as Pilhas a Combustível de Óxido Sólido (PaCOS), objeto deste trabalho, possuem todos os componentes no estado sólido e operam em altas temperaturas (entre $750{ }^{\circ} \mathrm{C}$ e $850{ }^{\circ} \mathrm{C}$ ) e fornecem voltagem de aproximadamente $1 \mathrm{~V}$. Para atingir maiores densidades de energia, várias unidades devem ser empilhadas em série. O contato elétrico entre duas pilhas unitárias adjacentes é promovido pelos interconectores, que também tem a função de separar e distribuir os gases combustível e oxidante no eletrodo durante a operação da PaCOS [3-7]. Nesse contexto, a escolha do material interconector deve ser feita de forma a garantir alguns requisitos básicos como baixo custo, boa condutividade elétrica e estabilidade química e estrutural nas condições de trabalho das PaCOS, além de ter que apresentar um coeficiente de expansão térmica compatível com os demais componentes da pilha [8-10].

Em relação aos materiais selecionados para a construção dos interconectores, nos últimos anos, os aços inoxidáveis tem se destacado [11-13]. Dentre as duas principais classes dos aços inoxidáveis, os aços ferríticos se destacam pelo custo inferior em relação à dos austeníticos (Tabelas 1 e 2), cuja adição de Ni em sua composição aumenta a estabilidade química, mas, por outro lado, aumenta também o custo e alteram as propriedades de expansão térmica do aço, o que torna essa última classe inviável para a fabricação dos interconectores [8, 14]. Os aços inoxidáveis ferríticos $(16-20 \% \mathrm{Cr})$, além do menor custo, possuem também boas propriedades mecânicas, elétricas e de usinagem, entretanto, em temperaturas elevadas, a camada passiva de $\mathrm{Cr}_{2} \mathrm{O}_{3(\mathrm{~s})}$, que garante boas propriedades de resistência à corrosão a todas as classes de aços inoxidáveis, se torna instável. $\mathrm{O}$ óxido de cromo superficial que em temperatura ambiente se apresenta no estado sólido, quando exposto à alta temperatura de operação da pilha, reage com o oxigênio e forma o óxido de cromo no estado gasoso, $\mathrm{CrO}_{2(\mathrm{~g})}$. Esse último, por volatilidade, migra para o catodo e causa a degradação da estrutura e a redução da vida útil da pilha, fenômeno conhecido como "envenenamento por cromo". Em consequência deste, outro fenômeno conhecido como oxidação/espalação também acontece na superfície dos aços inoxidáveis expostos a altas temperaturas. A redução na espessura da camada de $\mathrm{Cr}_{2} \mathrm{O}_{3}$ na superfície do aço permite o aparecimento de uma camada superficial de $\mathrm{Fe}_{2} \mathrm{O}_{3}$, causando a diminuição da condutividade elétrica da pilha [9, 10, 15-17]. Assim, vários processos tem sido desenvolvidos com o objetivo de bloquear a volatilidade de cromo da superfície dos aços inoxidáveis nas condições de funcionamento da PaCOS [9, 18]. Algumas ligas comerciais foram especialmente desenvolvidas para essas aplicações e mostraram bons resultados, como as ligas à base de níquel Inconel e os aços inoxidáveis Crofer 22APU e AISI 304, cujas composições químicas usuais são mostradas na Tabela 1. Todavia, o processo de fabricação e a presença de metais nobres nas composições dessas ligas aumentam seu custo relativo, principalmente para as ligas à base de níquel, já que esse elemento possui alto valor agregado e, portanto não atendem ao requisito de viabilidade econômica das PaCOS [19-21] (Tabela 2). Assim, uma opção promissora seria o revestimento dos aços ferríticos com materiais que atuem como barreira física à volatilização do cromo, mantendo a baixa resistência elétrica dessa classe de aços [20-28].

Tabela 1: Composição química $(\% \mathrm{~m} / \mathrm{m})$ dos principais ligas metálicas utilizadas como interconectores [22].

\begin{tabular}{c|c|c|c|c|c|c|c|c|c}
\hline Ligas/Elementos $(\% \mathbf{m} / \mathbf{m})$ & Fe & Ni & $\mathbf{C r}$ & $\mathbf{M n}$ & $\mathbf{A l}$ & $\mathbf{S i}$ & $\mathbf{W}$ & Mo & Outros \\
\hline AISI 430 & Base & - & 16 & 0,5 & - & 0,52 & - & 0,02 & \\
\hline Crofer22APU & Base & - & 23 & 0,6 & - & 0,05 & - & - & $0,08 \mathrm{Ti}-0,06 \mathrm{La}$ \\
\hline AISI 304 & Base & 8 & 18 & 2 & - & 1 & - & - & \\
\hline Inconel & 3 & Base & 23 & 0,5 & - & 0,4 & 5 & 2 & \\
\hline
\end{tabular}


Tabela 2: Custo de alguns metais e aços (consultado em janeiro de 2020) [29].

\begin{tabular}{|c|c|}
\hline Amostra & Preço $(\mathrm{R} \$ / \mathrm{Kg})$ \\
\hline $\mathrm{Ni}$ & 43,23 \\
\hline $\mathrm{Cr}$ & 31,72 \\
\hline $\mathrm{Fe}$ & 0,18 \\
\hline Aço AISI430 & 1,30 \\
\hline Aço AISI304 & 3,90 \\
\hline Crofer & 6,68 \\
\hline Inconel & 27,6 \\
\hline
\end{tabular}

Em se tratando dos revestimentos, estes podem ser obtidos pela técnica de eletrodeposição seguida de oxidação em altas temperaturas [6,30-32]. O processo envolve a deposição de um revestimento ou liga metálica sobre uma superfície condutora por meio da eletrólise. Esse método de obtenção do filme protetor se destaca entre outros métodos de deposição por apresentar vantagens como a rápida taxa de deposição, boa relação custo-benefício e simplicidade de controle sobre parâmetros [33].

Para a deposição potenciostática o eletrólito deve apresentar uma concentração adequada das espécies de interesse a serem eletrodepositadas. Dentre elas, o cobalto e o manganês são metais de destaque uma vez que os óxidos dessas espécies, ou mesmo a liga metálica formada entre ambos, possuem uma boa condutividade elétrica. Neste trabalho, o eletrólito, rico em íons $\mathrm{Co}^{2+} \mathrm{e} \mathrm{Mn}^{2+}$, foi obtido a partir da reciclagem de baterias de celular do tipo íon-Li de e eletrodepositados sobre a superfície do aço ferrítico AISI 430. O material foi obtido a partir do catodo da bateria que, geralmente, é um óxido misto de lítio que pode conter também $\mathrm{Co}, \mathrm{Mn}, \mathrm{Ni}$ e $\mathrm{Fe}$, depositado sobre uma fita de alumínio coletora de corrente $[34,35]$. O catodo representa aproximadamente $20 \%$ da composição de baterias e possui um alto valor econômico agregado chegando a 80.000 US/ton. em 2018 [36]. Esses metais apresentam também risco de toxicidade no meio ambiente, assim, o crescente aumento do número de celulares descartados de forma inadequada contribuem para o aumento da poluição ambiental provocada por metais como cobalto, lítio e manganês, dentre outros [37, 38]. Dessa forma, a obtenção de soluções ricas em cobalto e manganês a partir da reciclagem de baterias de celulares exauridas torna-se uma excelente alternativa para a redução de custos e risco ambiental [39-43].

Os revestimentos podem apresentar diferenças microestruturais devido aos diferentes pH's da solução, potencial aplicado durante a eletrodeposição ou até mesmo por variações da temperatura do tratamento térmico dos depósitos. Freitas e Garcia [43] estudaram a eletrodeposição potenciostática de cobalto por rota hidrometalúrgica. As maiores eficiências obtidas pelos autores foram de $95 \% \mathrm{em} \mathrm{pH}=5,4$. No entanto, uma pequena diminuição $(10-15 \%)$ é notada para os valores de eficiência de carga em potenciais $-1,1 \mathrm{~V}$ e $-1,0 \mathrm{~V}$ quando o pH da solução é reduzido para $\mathrm{pH}=2,7$. Segundo os autores, em pH's muito ácidos, os eletrodepósitos de cobalto passam por um estágio intermediário em que as espécies são adsorvidas por moléculas de hidrogênio e a reação subsequente é a redução das espécies adsorvidas para cobalto metálico. Resultados mostraram filmes menos resistentes a corrosão para amostras provenientes de soluções mais ácidas, devido à inclusão de hidrogênio na estrutura cristalina dos depósitos. Em um estudo posterior, Freitas et al. [42] destacam a dependência do processo de nucleação e crescimento dos filmes de cobalto de acordo com o pH da solução eletrolítica. Em $\mathrm{pH}=2,7$ os filmes se mostraram menos porosos que em $\mathrm{pH}=5,4$. Os autores mostram que para $\mathrm{pH}=2,7$ o modelo de nucleação e crescimento é bidimensional instantâneo, no qual os núcleos são formados instantaneamente sob o substrato e o filme apresenta morfologia mais homogênea. Em $\mathrm{pH}=$ 5,4 , o crescimento do filme tende a um mecanismo de nucleação tridimensional, lento e progressivo, com pequeno número de sítios ativos, o que resulta em um filme com grãos maiores e menos homogêneos.

Assim, o presente trabalho tem como objetivo estudar a eletrodeposição de ligas de Co-Mn na superfície do aço AISI 430 a partir de soluções preparadas com o catodo reciclado das BIL's $([\mathrm{Co}]=[\mathrm{Mn}]=0,02)$, para a construção de interconectores metálicos eficientes nas condições de operação das PaCOS. Para isso, serão estudadas as características microestruturais dos revestimentos por DRX, Microscopia Eletrônica de Varredura (MEV) e Espectroscopia de Energia Dispersiva (EED) após tratamento térmico a $800^{\circ} \mathrm{C}$ por $300 \mathrm{~h}$.

\section{MATERIAIS E MÉTODOS}

O material utilizado como substrato neste trabalho foi o aço inoxidável ferrítico AISI430, fornecido pela em- 
presa APERAM S. A. A composição nominal do aço fornecida pela empresa indica 16,22\% Cr, com adição de elementos de baixa liga como $\mathrm{Mn}$ e $\mathrm{Ni}$ abaixo de $0,3 \%$. Em forma de chapas laminadas, de espessura de 1 $\mathrm{mm}$, as amostras foram cortadas, pela Oficina Mecânica do Departamento de Química da UFMG, em dimensões de 20 × $20 \mathrm{~mm}$. Uma politriz DPU-10 Strues foi utilizada na etapa de lixamento superficial, com lixas d'água 400 e 600 (tamanho de grão). Após essa etapa, as amostras foram lavadas com detergente, em água corrente, água deionizada e álcool isopropílico, e, em seguida, secas com o auxílio de um soprador térmico HL 500 Steinel. O procedimento de limpeza é importante para eliminar defeitos superficiais e variações de composição devido a componentes residuais das lixas nas amostras, o que pode influenciar no desempenho da amostra durante o processo de oxidação [28]. Alem disso, esta etapa é necessária para retirar da superfície substancia apolares (como gorduras residuais da manipulação das amostras) que podem influenciar a condutividade superficial e influencia diretamente no processo de eletrodeposição aumentado o sobrepotencial de redução dos cátions metálicos.

Para o preparo da solução do eletrólito, duas baterias foram desmanteladas e os catodos passaram por processo de pré tratamento de lixiviação química utilizando os mesmo parâmetros descritos em trabalho anterior [36]. As concentrações dos metais para as soluções provenientes da dissolução dos catodos das baterias foram obtidas por espectroscopia de absorção atômica, em um espectrofotômetro de absorção atômica modelo AA-1275 a da marca Intralab, no Laboratório de Absorção Atômica do Departamento de Química da UFMG. Ambas concentrações de íons $\mathrm{Co}^{2+}$ e $\mathrm{Mn}^{2+}$ nas soluções foram ajustadas $0,02 \mathrm{M}$ com adição de água destilada. Os valores de $\mathrm{pH}$ ajustados para 3,0 e 3,5, usando uma solução de $\mathrm{NaOH}$ 0,5 M previamente preparada. A concentração foi proposta a partir de resultados de trabalho anterior, no qual foram estudadas soluções com diferentes proporções de $\mathrm{Mn}$ e Co, obtidas pelo mesmo processo de reciclagem via rota hidrometalúrgica [36].

As medidas eletroquímicas deste trabalho foram realizadas pelas técnicas de Voltametria Cíclica e Eletrodeposição Potenciostática. Para as duas técnicas, os experimentos foram conduzidos em uma típica célula eletroquímica de três eletrodos, em que os eletrodos de trabalho foram as amostras de aço inoxidável ferrítico AISI430; o eletrodo de referência $\mathrm{Ag} / \mathrm{AgCl}(\mathrm{KCl} 3 \mathrm{M})$; o eletrodo auxiliar de Platina $\left(1,0 \mathrm{~cm}^{2}\right)$ e o eletrólito $40 \mathrm{~mL}$ da solução reciclada. As voltametrias cíclicas foram realizadas com o objetivo de identificar os potenciais de redução do cobalto e do manganês nas condições de concentração e pH's do eletrólito. As eletrodeposições foram realizadas aplicando o potencial de $-1,5 \mathrm{~V}$, por tempo necessário para que a densidade de carga alcançasse $20 \mathrm{C} / \mathrm{cm}^{2}$, para o potencial aplicado. Com o objetivo de especificar a eficiência de carga no processo $(\varepsilon)$, valores de densidade de carga catódica $\left(\mathrm{Q}_{\mathrm{c}}\right)$ e anódica $\left(\mathrm{Q}_{\mathrm{a}}\right)$ foram obtidos integrando-se as áreas das regiões catódica e anódica dos voltamogramas (Equação 1), para as duas condições de $\mathrm{pH}$. As cargas $\mathrm{Q}_{\mathrm{c}} \mathrm{e}$ $\mathrm{Q}_{\mathrm{a}}$ foram obtidas através da integral das áreas anódica (em vermelho) e catódica (em azul), conforme mostra a Figura 1.

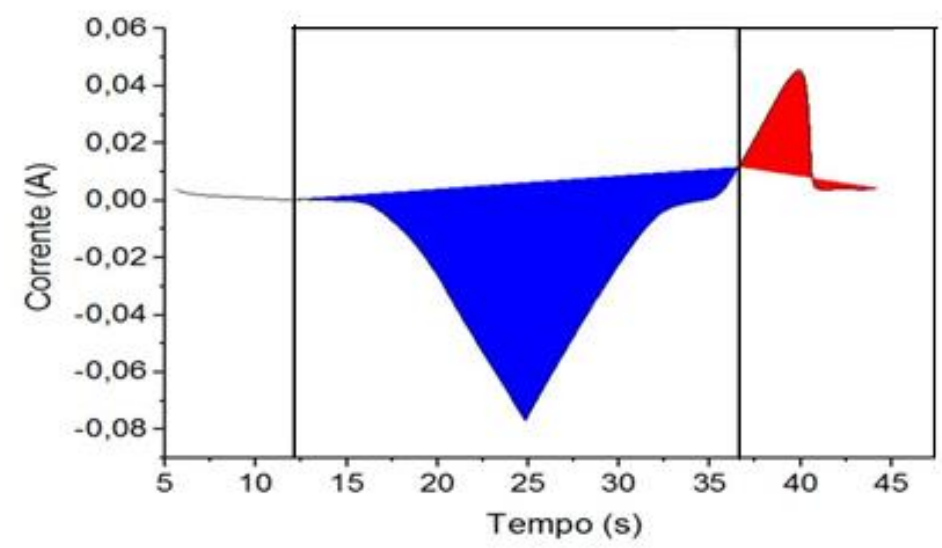

Figura 1: Gráfico das áreas anódica (vermelho) e catódica (azul) para o cálculo da eficiência de carga.

$$
\varepsilon(\%)=\frac{\int i_{a} d t}{\int i_{c} d t} x 100
$$

Em que $i_{a}$ e $i_{c}$ são as densidades de corrente anódica e catódica, respectivamente. 
Os revestimentos metálicos obtidos aplicando-se o potencial de $-1,5 \mathrm{~V}$ foram submetidos a tratamento térmico de oxidação a $800{ }^{\circ} \mathrm{C}$ por 300 h. Essas amostras foram, após a oxidação, caracterizadas por DRX para determinação das fases cristalográficas presentes, e por MEV e EED para estudo da morfologia e composição química das amostras. As medidas de DR-X foram realizadas no Departamento de Química da UFMG, com um difratômetro Rigaku, modelo Geigerflex. A varredura foi feita de $30^{\circ}$ a $65^{\circ}(2 \theta)$, radiação $\mathrm{CuK} \alpha$, com tubo de cobre, tensão de $40 \mathrm{kV}$, corrente $40 \mathrm{~mA}$, e a velocidade para o método de rotina de $1^{\circ}$ (20) / min. Os picos de difração característicos foram identificados utilizando o software Crystallographica Search-Match. As imagens de MEV apresentadas neste trabalho foram adquiridas no Centro de Microscopia da UFMG no aparelho JEOL JSM 6360LV com detector de elétrons secundários e EED com modo alto vácuo operando entre $10^{-6}$ e $10^{-7}$ torr e modo baixo vácuo operando a $10^{-2}$ torr. Com o objetivo de se entender melhor a integridade microestrutural dos revestimentos formados, imagens de MEV foram obtidas em aumentos de 2500X e 5000X.

\section{RESULTADOS}

\subsection{Medidas Eletroquímicas}

A Figura 2 mostra em destaque as curvas de redução catódica dos eletrólitos obtidos da reciclagem das baterias para a concentração estudada nos pH's 3,0 e 3,5.

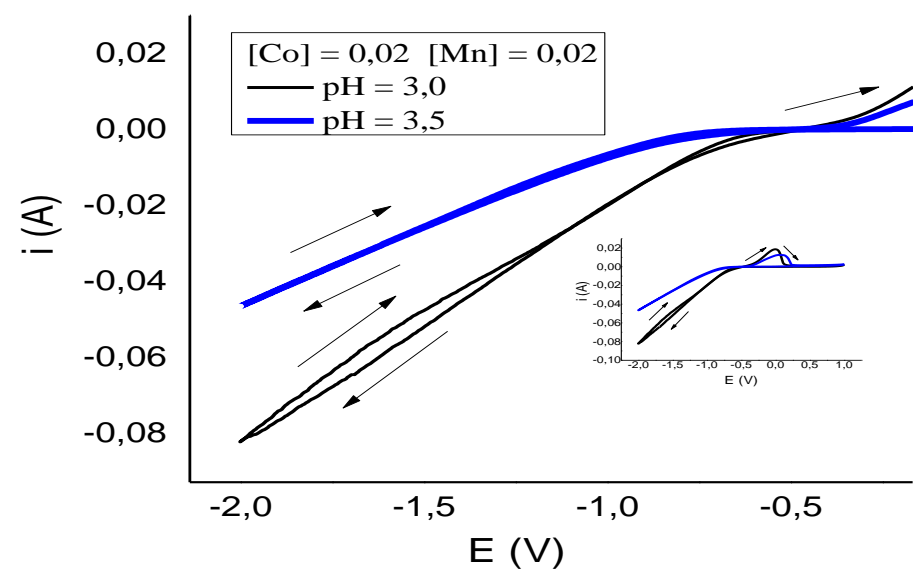

Figura 2: Voltametria cíclica do aço AISI em meio à solução $[\mathrm{Co}]=0,02[\mathrm{Mn}]=0,02$ a partir da dissolução do catodo reciclado das BIL's em $\mathrm{pH}=3,0$ e $\mathrm{pH}=3,5$.

Pode-se observar que a corrente de redução é atuante para potenciais mais negativos que $-0,5 \mathrm{~V}$, em ambos os pH's. Todavia, para o $\mathrm{pH}=3,0$ há uma maior contribuição da corrente catódica relacionada à redução do hidrogênio em paralelo à redução dos íons $\mathrm{Co}^{2+}$ e $\mathrm{Mn}^{2+}$, como pode ser visto pela maior inclinação da curva. Esse fato pode indicar que durante a formação do depósito houve um estágio intermediário de adsor-

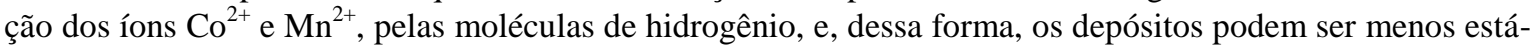
veis micro estruturalmente $[43,44]$. Dados de eficiência de carga durante o processo de redução/ eletrodeposição catódica são mostrados na Figura 3. Pode-se observar que uma menor eficiência é obtida para o $\mathrm{pH}$ mais ácido. Esse comportamento é explicado pelas reações de desprendimento de hidrogênio que comprometem a eficiência total do processo, uma vez que parte da carga é utilizada para a redução de hidrogênio [43]. As microestruturas dos revestimentos formados com potencial aplicado de -1,5 V foram estudadas nas duas condições de $\mathrm{pH}$, e são mostradas na seção seguinte. 


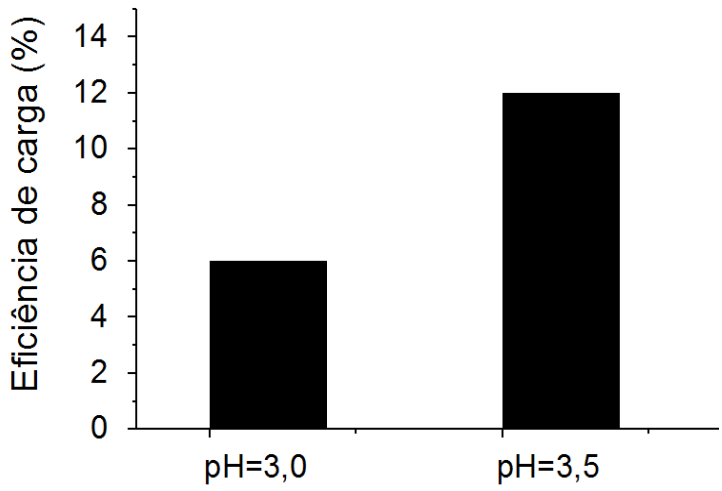

Figura 3: Eficiência de carga para os voltamogramas mostrados na Figura 2.

\subsection{Difração de Raios-X}

As amostras eletrodepositadas e oxidadas a $800{ }^{\circ} \mathrm{C}$ por $300 \mathrm{~h}$ foram submetidas à análise de DRX para identificação das fases cristalográficas conforme mostrado na Figura 4. Nota-se que diferentes fases de óxido protetor foram formadas para as amostras eletrodepositadas em diferentes $\mathrm{pH}$ 's. Para o pH mais ácido, a fase formada foi $\mathrm{MnCo}_{2} \mathrm{O}_{4}$ enquanto que para o $\mathrm{pH}=3,5$, a fase formada foi de $\mathrm{Co}_{3} \mathrm{O}_{4}[45,46]$. As fichas cristalográficas comumente utilizadas para óxidos provenientes da oxidação do aço substrato $\mathrm{Fe}_{2} \mathrm{O}_{3}, \mathrm{Cr}_{2} \mathrm{O}_{3} \mathrm{e}$, apresentam picos correspondentes muitos próximos entre si, o que pode gerar dúvidas quanto à indicação das fases cristalográficas apropriadas $[9,36,47]$. No entanto, neste trabalho o objetivo das análises por DRX é a identificação da fase protetora em detrimento das fases de óxidos provenientes do substrato. Posteriormente, para essas amostras a presença e/ou a proporção de cobalto, manganês, ferro e cromo na composição do depósito podem ser melhor analisadas por análises semiquantitativas de MEV e EED conforme será mostrado na seção seguinte.

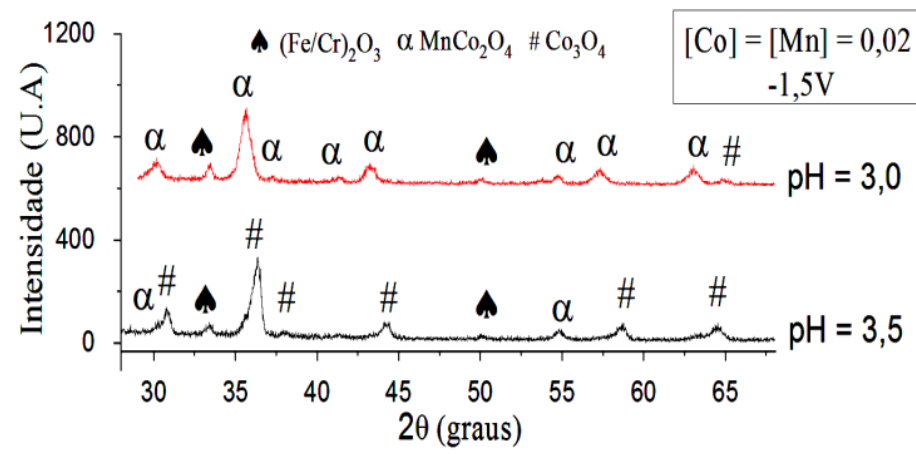

Figura 4: Difratogramas de raios- $\mathrm{X}$ para as amostras eletrodepositadas em $\mathrm{pH}=3,0$ e $\mathrm{pH}=3,5$ submetidas a $800{ }^{\circ} \mathrm{C}$ por $300 \mathrm{~h}$.

\subsection{Análise Microestrutural e de Composição Química dos revestimentos.}

Os mapas químicos composicionais da seção transversal das amostras obtidas pelo potencial de $-1,5 \mathrm{~V}$, em $\mathrm{pH}=3,0 \mathrm{e} \mathrm{pH}=3,5$, são mostrados na Figura 5. Em primeiro momento, observa-se nitidamente a presença do manganês apenas no revestimento em $\mathrm{pH}=3,0$, conforme Figura 5A, resultado que vai de acordo com a fase de $\mathrm{MnCo}_{2} \mathrm{O}_{4}$ identificada pela DRX (Figura 4). Vale ressaltar ainda, que não há a presença de Fe na superfície da amostra, mostrando que a camada recobriu o aço de maneira eficaz, apesar de ter apresentado menor eficiência de carga. O revestimento foi também eficiente em bloquear a volatilidade do $\mathrm{Cr}$, retido abaixo do revestimento pelo $\mathrm{Mn}$, fato comprovado pela maior espessura de composição do Cr observada nessa amostra.

Para a amostra em $\mathrm{pH}=3,5$, observa-se um comportamento distinto. Ainda que mais espesso, não é observada a presença do $\mathrm{Mn}$ na composição do revestimento (Figura 5B), que é, portanto, composto por $\mathrm{Co}_{3} \mathrm{O}_{4}$, conforme evidenciado no difratograma da Figura 4. Apenas uma fina camada de $\mathrm{Cr}$ pode ser observada, fato decorrente da volatilização desse elemento na superfície do aço. Além disso, nessa condição, é possível notar 
a presença de Fe na superfície da amostra, mostrando que o revestimento não protegeu toda a superfície do aço e pode ter também comprometido a condutividade elétrica do material pela formação de $\mathrm{Fe}_{2} \mathrm{O}_{3}$ na superfície. Assim, nessa condição, apesar de mais espesso, o revestimento não foi capaz de bloquear a perda do cromo por volatilidade. A menor espessura da camada de cromo, mostrada na figura 5B, é explicada pelo fato de parte do cromo ter sido volatilizado.

Imagens ampliadas da área superficial das amostras ratificam esse comportamento (Figura 6). Para a amostra em $\mathrm{pH}=3,0$, grãos menores e distribuídos homogeneamente contribuem para uma menor porosidade e são capazes de reter o cromo internamente, enquanto em $\mathrm{pH}=3,5$ grãos maiores e heterogêneos permitem a passagem intersticial do óxido de cromo gasoso [36, 48]. Assim, pode-se dizer que uma pequena variação no $\mathrm{pH}($ de $\mathrm{pH}=3,5$ para $\mathrm{pH}=3,0)$ promoveu uma grande melhora na microestrutura do revestimento, mesmo com uma pequena perda de eficiência.

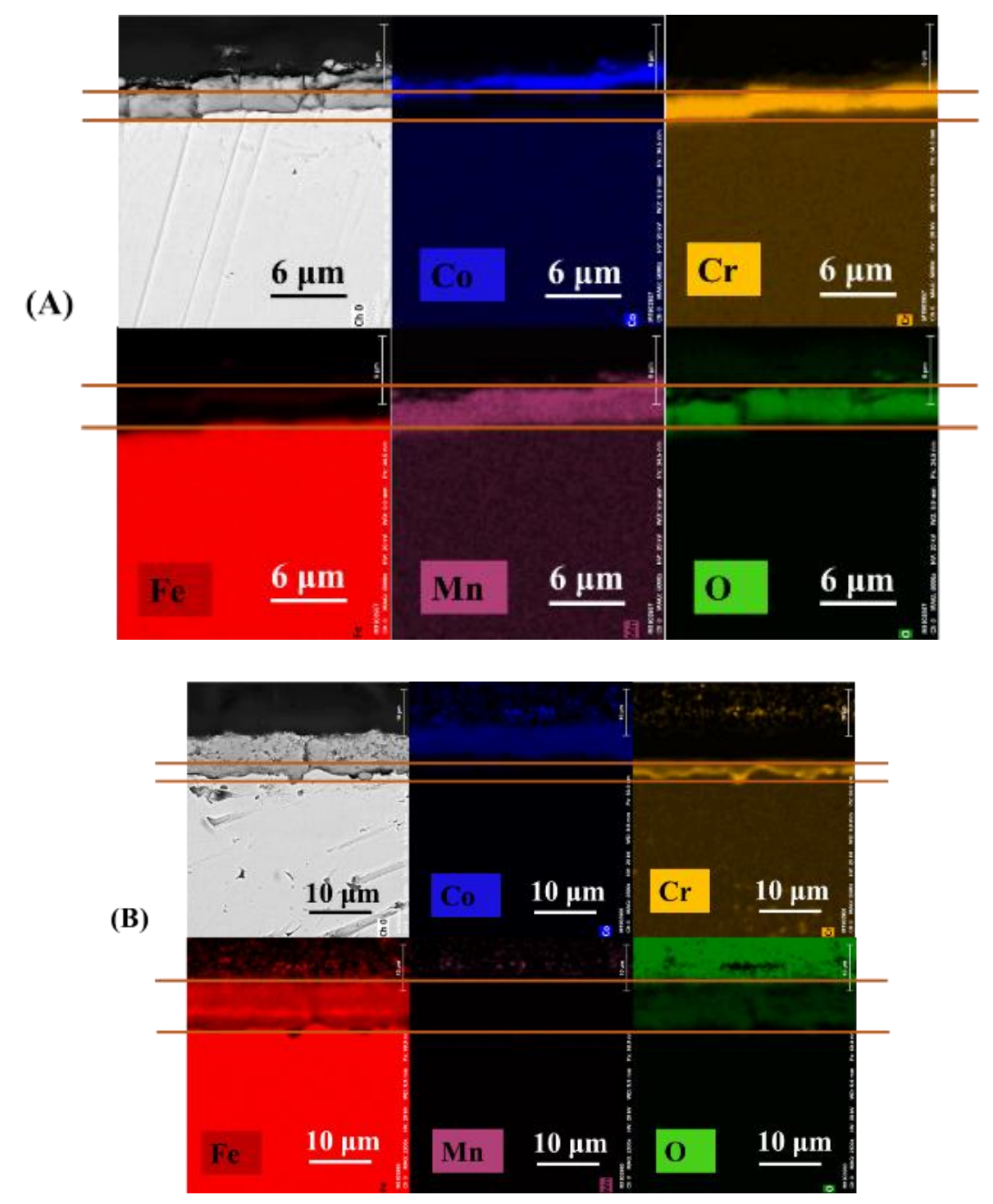

Figura 5: Mapa químico composicional fornecido por EED para as amostras eletrodepositadas em: (A) $\mathrm{pH}=3,0$ e (B) $\mathrm{pH}=3,5$ 


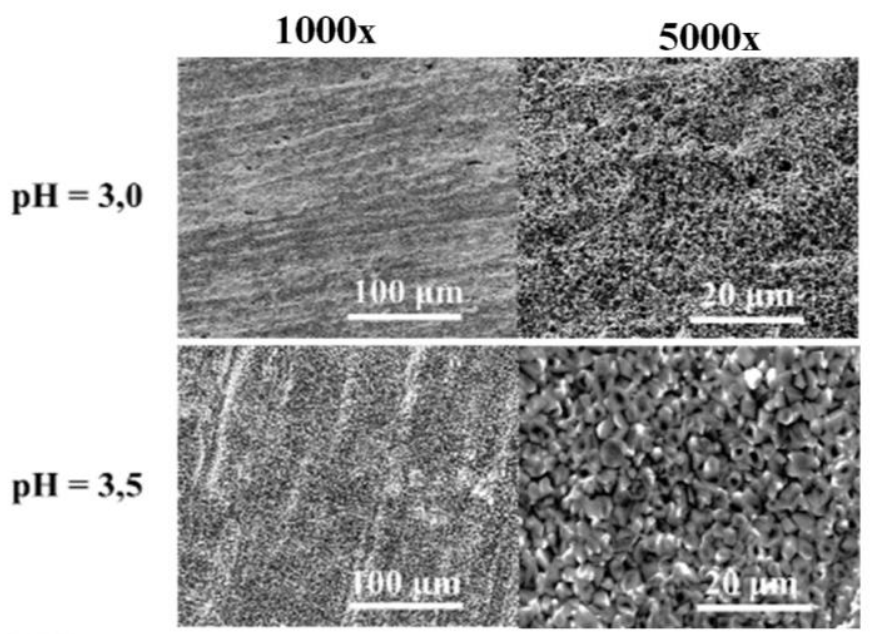

Figura 6: Micrografia Eletrônica de Varredura (1000X e 5000X) para as amostras eletrodepositadas em $\mathrm{pH}=3,0$ e $\mathrm{pH}=$ 3,5 submetidas a $800^{\circ} \mathrm{C}$ por $300 \mathrm{~h}$.

\section{CONCLUSÕES}

O método de obtenção de filmes protetores a partir de catodos reciclados, por eletrodeposição potenciostática se mostrou eficiente na obtenção de filmes com características microestruturais adequadas para reter a volatilização indesejável do cromo. Evitando desta forma o envenenamento do catodo durante o funcionamento das PaCOS.

O potencial aplicado de $-1,5 \mathrm{~V}$ foi suficiente para a eletrodeposição dos íons metálicos Co e Mn na superfície do aço inoxidável AISI430. Para as condições de eletrodeposição estudadas, na amostra obtida em $\mathrm{pH}=3,0$, obteve-se um revestimento composto por $\mathrm{MnCo}_{2} \mathrm{O}_{4}$ o qual apresentou uma microestrutura eficiente em bloquear a volatilidade do cromo. Já para o $\mathrm{pH}$ ligeiramente maior $(\mathrm{pH}=3,5)$, a fase cristalográfica predominante do revestimento foi o $\mathrm{Co}_{3} \mathrm{O}_{4}$ com microestrutura de grãos maiores e heterogêneos que possibilitou o escape de parte do cromo. A pequena mudança de $\mathrm{pH}=3,5$ para $\mathrm{pH}=3,0$ ocasionou uma grande melhora na microestrutura do revestimento, mesmo com uma pequena perda de eficiência de carga na deposição.

Assim, o trabalho aqui apresentado contribui para o desenvolvimento de um revestimento de baixo custo para aplicação em interconectores das PaCOS além de contribuir para a diminuição da poluição ambiental uma vez que retira dos aterros sanitários as baterias que muitas vezes são descartadas de maneira inadequadas e que comprometem o meio ambiente.

\section{AGRADECIMENTOS}

Agradecimentos a Coordenação de Aperfeiçoamento de Pessoal de Nível Superior (CAPES), ao Conselho Nacional de Desenvolvimento Científico e Tecnológico (CNPq) e à Fundação de Amparo à Pesquisa de Minas Gerais (FAPEMIG) pelo suporte financeiro. Ao Centro de Microscopia da UFMG (CM-UFMG) pelo suporte técnico e à APERAM (Timóteo-Brasil) pelo fornecimento das amostras e sua composição.

\section{BIBLIOGRAFIA}

[1] CORALli, A., MIRANDA, P.E.V. " Balanço de planta para microgerador PaCOS alimentado com etanol" Matéria, e-11944, 2017.

[2] LIS, B. "Selected aspects of the design and diagnostics of solid oxide fuel cells," E3S Web Conf., vol. 10, p. 00128, Oct., 2016.

[3] MAHMUD, L.S., MUCHTAR, A., SOMALU, M.R. "Challenges in fabricating planar solid oxide fuel cells: A review,” Renew. Sustain. Energy Rev., v. 72, pp. 105-116, May., 2017. 
[4] PIANKO-OPRYCH, P., JAWORSKI, Z., KENDALL, K. "Cell, stack and system modelling," in HighTemperature Solid Oxide Fuel Cells for the 21 st Century, 2nd ed., H.-T. S. O. F. C. for the 21 st Century, Ed. Elsevier Ltd, pp. 407-460, 2016.

[5] AMARAL, A.A., MATOS, F.F., BENEDICTO, J.P., et al., "Eficiência Teórica de Pilhas a Combustível do tipo PaCOS", Matéria, v. 12, n. 1, pp. 54-64, 2007.

[6] CROCHEMORE, G.B., ANTUNES, F.C., SOUZA, D.P.F., "Propriedades elétricas e microestrutural de Céria dopada com $\mathrm{Gd}+3$ e Y+3 para aplicação como eletrólitos em pilhas a combustível", Matéria, v. 13, n. 3, pp. 495-511, 2008.

[7] VENÂNCIO, S.A., GUTIERRES, T.F., SARRUF, B.J.M., et al., "Oxidação direta do etanol no anodo de PaCOS", Matéria, v. 13, n. 3, pp. 560-568, 2008.

[8] SILVA, M.A., ALENCAR, M.G.F., FIÚZA, R.P., et al., "Preparação e Avaliação de Célula a Combustível do Tipo PaCOS Unitária com Ânodo a base de Níquel e Cobalto", Matéria, v. 12, pp. 72-85, 2007.

[9] JIA, C., WANG, Y., MOLIN, S., et al. "High temperature oxidation behavior of SUS430 SOFC interconnects with Mn-Co spinel coating in air," J. Alloys Compd., v. 787, pp. 1327-1335, May., 2019.

[10] LI, J. et al., "Investigation of $\mathrm{MnCu} 0.5 \mathrm{Co} 1.5 \mathrm{O} 4$ spinel coated SUS430 interconnect alloy for preventing chromium vaporization in intermediate temperature solid oxide fuel cell," Int. J. Hydrogen Energy, v. 42, n. 26, pp. 16752-16759, Jun., 2017.

[11] SUN, Z.R., WANG, A.Y., NIKIFOROV, S., et al., "CuMn1.8O4 protective coatings on metallic interconnects for prevention of Cr-poisoning in solid oxide fuel cells," J. Power Sources, v. 378, pp. 125133, Feb., 2018.

[12] ANDERSON, H.U., TIETZ, F. "Interconnects," in High Temperature Solid Oxide Fuel Cells: Fundamentals, Design and Applications, S. C. Singhal and K. Kendall, Eds. Elsevier Science, pp. 173-195, 2003.

[13] JO, K.H., KIM, J.H., KIM, K.M., et al., "Development of a new cost effective Fe-Cr ferritic stainless steel for SOFC interconnect," Int. J. Hydrogen Energy, v. 40, n. 30, pp. 9523-9529, Aug., 2015.

[14] BIANCO, M., LINDER, M., LARRING, Y., et al., "Lifetime Issues for Solid Oxide Fuel Cell Interconnects," in Solid Oxide Fuel Cell Lifetime and Reliability: Critical Challenges in Fuel Cells, 1st ed., N. P. Brandon, P. Boldrin, and E. Ruiz-Trejo, Eds. Elsevier Ltd, pp. 121-144, 2017.

[15] DEMENEVA, N.V., KONONENKO, O.V., MATVEEV, D.V., et al., "Composition-gradient protective coatings for solid oxide fuel cell interconnectors," Mater. Lett., v. 240, pp. 201-204, 2019.

[16] TALIC, B., HENDRIKSEN, P.V., WIIK, K., et al., "Thermal expansion and electrical conductivity of Fe and Cu doped MnCo2O4 spinel," Solid State Ionics, vol. 326, pp. 90-99, Nov., 2018.

[17] MAHATO, N., BANERJEE, A., GUPTA, A., et al., "Progress in material selection for solid oxide fuel cell technology: A review," Prog. Mater. Sci., v. 72, pp. 141-337, 2015.

[18] YU, Y.T., ZHU, J.H., BATES, B.L. "Conductive spinels derived from Co-Mn based alloy precursor for SOFC cathode-side contact application," Int. J. Hydrogen Energy, v. 45, n. 51, pp. 27745-27753, 2020.

[19] HSU, C., YEH, A., SHONG, W., et al. "Development of advanced metallic alloys for solid oxide fuel cell interconnector application,” J. Alloys Compd., v. 656, pp. 903-911, Jan., 2016.

[20] WU, J., LIU, X. "Recent Development of SOFC Metallic Interconnect," J. Mater. Sci. Technol., v. 26, pp. 293-305, Apr., 2010.

[21] BEDNARZ, M., et al., "High-temperature oxidation of the Crofer $22 \mathrm{H}$ ferritic steel with $\mathrm{Mn} 1.45 \mathrm{Co} 1.45 \mathrm{Fe} 0.1 \mathrm{O} 4$ and $\mathrm{Mn} 1.5 \mathrm{Co} 1.5 \mathrm{O} 4$ spinel coatings under thermal cycling conditions and its properties," Mater. Chem. Phys., v. 225, n. January 2018, pp. 227-238, 2019.

[22] SHAIGAN, N., QU, W., IVEY, D.G., et al., "A review of recent progress in coatings, surface modifications and alloy developments for solid oxide fuel cell ferritic stainless steel interconnects," J. Power Sources, v. 195, n. 6, pp. 1529-1542, 2010.

[23] MOLIN, S. et al., "Microstructural and electrical characterization of Mn-Co spinel protective coatings for solid oxide cell interconnects," J. Eur. Ceram. Soc., v. 37, pp. 4781-4791, Dec., 2017.

[24] CHEN, G. et al., "Mn1.4Co1.4Cu0.2O4 spinel protective coating on ferritic stainless steels for solid oxide fuel cell interconnect applications," J. Power Sources, v. 278, pp. 230-234, 2015.

[25] GRÜNWALD, N., SEBOLD, D., SOHN, Y.J., et al., "Self-healing atmospheric plasma sprayed Mn1.0Co1.9Fe0.1O4 protective interconnector coatings for solid oxide fuel cells," J. Power Sources, v. 363, pp. 185-192, 2017. 
[26] GRÜNWALD, N., SOHN, Y.J., YIN, X., et al., "Microstructure and phase evolution of atmospheric plasma sprayed Mn-Co-Fe oxide protection layers for solid oxide fuel cells," J. Eur. Ceram. Soc., v. 39, no. 2-3, pp. 449-460, 2019.

[27] PURANEN, J. et al., "High temperature oxidation tests for the high velocity solution precursor flame sprayed manganese-cobalt oxide spinel protective coatings on SOFC interconnector steel," Int. J. Hydrogen Energy, v. 40, pp. 6216-6227, May., 2015.

[28] HOSSEINI, N., ABBASI, M.H., KARIMZADEH, F., et al., "Development of Cu1.3Mn1.7O4 spinel coating on ferritic stainless steel for solid oxide fuel cell interconnects," J. Power Sources, v. 273, pp. 10731083, 2014.

[29] “ARGUS MEDIA GROUP.” http://www.metalprices.com. Acesso em 14 de Janeiro, 2020.

[30] MAH, J.C.W., MUCHTAR, A., SOMALU, M.R., et al., "Metallic interconnects for solid oxide fuel cell: A review on protective coating and deposition techniques," Int. J. Hydrogen Energy, v. 42, n. 14, pp. 9219-9229, Apr., 2017.

[31] APELT, S., ZHANG, Y., ZHU, J.H., et al., "Electrodeposition of Co-Mn3O4 composite coatings," Surf. Coatings Technol., v. 280, pp. 208-215, 2015.

[32] PINTO, R., CARMEZIM, M.J., MONTEMOR, M.F. "Electrodeposition and isothermal aging of Co and Mn layers on stainless steel for interconnectors: Initial stages of spinel phase formation," J. Power Sources, v. 255, pp. 251-259, Jun., 2014.

[33] LIU, F., DENG, Y., HAN, X., et al. "Electrodeposition of metals and alloys from ionic liquids," $J$. Alloys Compd., v. 654, pp. 163-170, Jan., 2016.

[34] DING, Y., ZHANG, S., LIU, B., et al., "Recovery of precious metals from electronic waste and spent catalysts: A review," Resour. Conserv. Recycl., v. 141, pp. 284-298, 2019.

[35] YANG, Y., HUANG, G., XU, S., et al., "Thermal treatment process for the recovery of valuable metals from spent lithium-ion batteries," Hydrometallurgy, v. 165, pp. 390-396, Oct., 2016.

[36] GONÇALVES, S.L.A., GARCIA, E.M., TARÔCO, H.A., et al., "Obtaining Mn-Co Alloys in AISI 430 Steel from Lithium-Ion Battery Recycling: Application in SOFC Interconnectors," ChemEngineering, v. 4, n. 1, p. 10, Feb., 2020.

[37] ZHENG, X. et al., "A Mini-Review on Metal Recycling from Spent Lithium Ion Batteries," Engineering, v. 4, pp. 361-370, Jun., 2018.

[38] ZENG, X., LI, J., SINGH, N. "Recycling of Spent Lithium-Ion Battery: A Critical Review," Crit. Rev. Environ. Sci. Technol., v. 44, pp. 1129-1165, May., 2014.

[39] ALMEIDA, J.R., et al., "Composition analysis of the cathode active material of spent Li-ion batteries leached in citric acid solution: A study to monitor and assist recycling processes," Sci. Total Environ., v. 685, pp. 589-595, 2019.

[40] GARCIA, E.M., SANTOS, J.S., PEREIRA, E.C., et al. FREITAS, "Electrodeposition of cobalt from spent Li-ion battery cathodes by the electrochemistry quartz crystal microbalance technique," J. Power Sources, v. 185, n. 1, pp. 549-553, 2008.

[41] BARBIERI, E.M.S., LIMA, E.P.C., CANTARINO, S.J., et al., "Recycling of spent ion-lithium batteries as cobalt hydroxide, and cobalt oxide films formed under a conductive glass substrate, and their electrochemical properties," J. Power Sources, v. 269, n. March, pp. 158-163, 2014.

[42] FREITAS, M.B.J.G., CELANTE, V.G., PIETRE, M.K. "Electrochemical recovery of cobalt and copper from spent Li-ion batteries as multilayer deposits," J. Power Sources, v. 195, n. 10, pp. 3309-3315, 2010.

[43] FREITAS, M.B.J.G., GARCIA, E.M. "Electrochemical recycling of cobalt from cathodes of spent lithium-ion batteries," J. Power Sources, v. 171, n. 2, pp. 953-959, 2007.

[44] GARCIA, E.M. "AÇO AISI 430 RECOBERTO COM COBALTO DE PILHAS DE CELULAR: USO COMO INTERCONECTOR PARA PILHAS A COMBUSTÍVEL DE ÓXIDO SÓLIDO,” Universidade Federal de Minas Gerais, 2012.

[45] TALIC, B., MOLIN, S., WIIK, K., et al. "Comparison of iron and copper doped manganese cobalt spinel oxides as protective coatings for solid oxide fuel cell interconnects," J. Power Sources, v. 372, n. October, pp. 145-156, 2017.

[46] HU, Y.Z. et al., "Aerosol sprayed Mn 1.5 Co $1.5 \mathrm{O} 4$ protective coatings for metallic interconnect of solid oxide fuel cells," Int. J. Hydrogen Energy, v. 41, n. 44, pp. 20305-20313, 2016.

[47] TOWNSEND, M.C. et al., "Download (1)," BMC Public Health, v. 2, n. 1. pp. 1-12, 2014. 
[48] DAYAGHI, A.M., ASKARI, M., RASHTCHI, H., et al. "Fabrication and high-temperature corrosion of sol-gel Mn/Co oxide spinel coating on AISI 430," Surf. Coatings Technol., v. 223, pp. 110-114, 2013.

[49] VENÂNCIO, S.A., MIRANDA, P.E.V., "Solid oxide fuel cell anode for the direct utilization of ethanol as a fuel”, Scripta Materialia, v. 65, n. 12, pp. 1065-1068, 2011.

\section{ORCID}

Sicele Luciana Abreu Gonçalves Eric Marsalha Garcia

https://orcid.org/0000-0002-5371-6040

Hosane Aparecida Taroco

https://orcid.org/0000-0002-3731-7568

Tulio Matencio

https://orcid.org/0000-0002-8744-9200

https://orcid.org/0000-0002-5660-8125 